\title{
Estimation of the cost of electro-mechanical equipment for small hydropower plants - review and comparison of methods
}

\author{
Seweryn Lipiński ${ }^{1, *}$, and Tomasz Olkowski ${ }^{1}$ \\ ${ }^{1}$ Department of Electric and Power Engineering, Electronics and Automation, Faculty of Technical Sciences, \\ University of Warmia and Mazury in Olsztyn, 11 Oczapowskiego St., 10-736 Olsztyn, Poland
}

\begin{abstract}
The estimate of the cost of electro-mechanical equipment for new small hydropower plants most often amounts to about $30-40 \%$ of the total budget. In case of modernization of existing installations, this estimation represents the main cost. This matter constitutes a research problem for at least few decades. Many models have been developed for that purpose. The aim of our work was to collect and analyse formulas that allow estimation of the cost of investment in electro-mechanical equipment for small hydropower plants. Over a dozen functions were analysed. To achieve the aim of our work, these functions were converted into the form allowing their comparison. Then the costs were simulated with respect to plants' powers and net heads; such approach is novel and allows deeper discussion of the problem, as well as drawing broader conclusions. The following conclusions can be drawn: significant differences in results obtained by using various formulas were observed; there is a need for a wide study based on national investments in small hydropower plants that would allow to develop equations based on local data; the obtained formulas would let to determinate the costs of modernization or a new construction of small hydropower plant more precisely; special attention should be payed to formulas considering turbine type.
\end{abstract}

\section{Introduction}

A proper assessment of investment cost can be regarded as crucial in any project; investment in small hydropower plant is no exception. Generally, this cost can be split into two parts. One of them is the sum of the cost of civil engineering works (land purchase, infrastructure, labour, etc.), which is extremely hard to estimate as it is highly dependent on local conditions in many aspects (e.g. difficulty of access or local material and labour costs) $[1,2]$. The second component is the cost of electro-mechanical equipment, which, as indicated by the literature research [2-14], can be better estimated.

The cost of electro-mechanical equipment for new small hydropower plants most often amounts to about $30-40 \%$ of the total budget [15]. In case of modernization of existing small hydro installations, this estimation represents the main cost.

The aim of our work was to analyse mathematical formulas that allow estimating the cost of investment in electro-mechanical equipment for small hydropower plants.

\section{Methodology}

To achieve the aim of our work, chosen cost functions were converted into the form allowing their comparison.
General rule, linking all expressions proposed in literature is their exponential form, i.e. cost $(C)$ is given as multiplication of exponential functions where power of plant $(P)$ and its net head $(H)$ are bases while different constant coefficients, obtained on the basis of real data, are exponents [3-13]. It means that the generalized formula can be given in a following form:

$$
C=a \cdot P^{b} \cdot H^{c},
$$

where $a, b$ and $c$ are the above mentioned constant coefficients. Only Singal and Saini [9] decided to divide the cost into four components but each of these components was still given in exponential form.

We decided to use US dollars (\$) as the currency (converted with the use of the exchange rate from the year of the publication of each of the considered formulas) and not to use specific cost as this is the approach most commonly used in the literature.

\section{Analysed formulas}

Gordon and Penman [3] proposed first formula destined for the estimation of electro-mechanical equipment cost in 1979. Since then, many others have been developed for that purpose. The basic approach is based on the value of power of the small hydropower plant and on its net head; this approach was used in works by Gulliver

\footnotetext{
* Corresponding author: seweryn.lipinski@uwm.edu.pl
} 
and Dotan [4], Whittington et al. [5], Voros et al. [6], Papantonis [7], Gordon [8], Kaldellis [9], Singal and Saini [10], and Aggidis et al. [11]. Ogayar and Vidal [12] took into account also turbine type (Kaplan, SemiKaplan, Francis or Pelton) while Cavazzini et al. [13] supplemented this approach with the use of design flow rate (but without distinction between Kaplan and SemiKaplan turbines).

The formulas obtained with the use of methodology described above are given in Table 1 . We analysed only correlations that are indicated as those including only the cost of electro-mechanical equipment, what decreased their number from over a dozen to five only.

\section{Results and discussion}

Based on equations from Table 1 the costs were simulated with respect to plants' powers and net heads. Obtained results are shown in Fig. 1 and Fig. 2.

Fig. 1 shows cost with respect to plant power for three values of net heads $(5,25$ and $100[\mathrm{~m}])$. Fig. 2

A
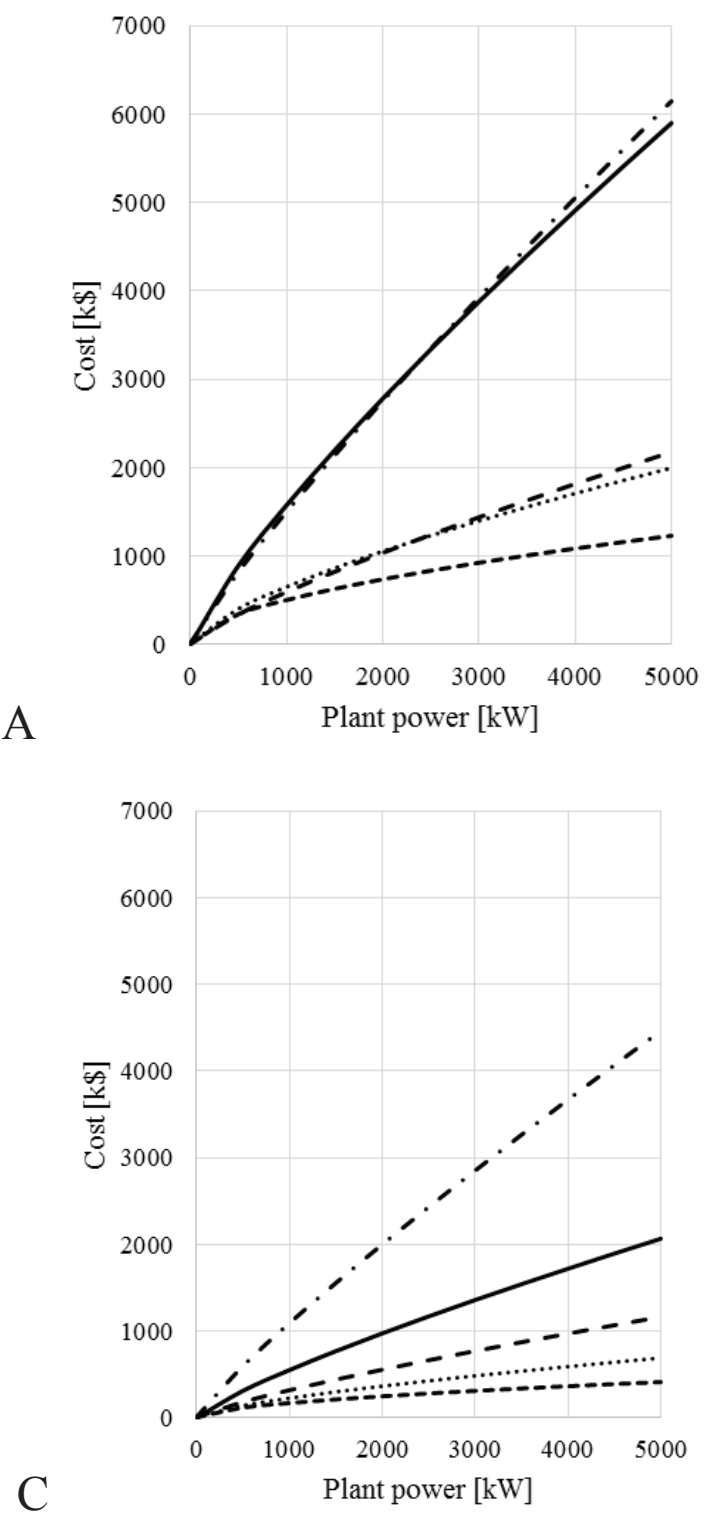

presents cost with respect to net head for four values of plant power $(5[\mathrm{~kW}], 100[\mathrm{~kW}], 500[\mathrm{~kW}]$ and $2[\mathrm{MW}])$.

Table 1. Literature functions the estimation of the cost of electro-mechanical equipment for small hydropower plants.

\begin{tabular}{|c|c|}
\hline Authors & $\begin{array}{c}\text { Investment costs } C[\$] \text { in the } \\
\text { function of power output } \\
P[\mathrm{~kW}] \text { and net head } H[\mathrm{~m}]\end{array}$ \\
\hline Gordon and Penman [4] & $C=9000 \cdot P^{0.7} \cdot H^{-0.35}$ \\
\hline Gulliver and Dotan [5] & $C=9600 \cdot P^{0.82} \cdot H^{-0.35}$ \\
\hline Kaldellis [10] & $C=4125 \cdot P^{0.878} \cdot H^{-0.107}$ \\
\hline Singal and Saini [11] & $\begin{array}{c}1180 \cdot P^{0.8145} \cdot H^{-0.2083}+ \\
613 \cdot P^{0.8108} \cdot H^{-0.2118}+ \\
281 \cdot P^{0.8197} \cdot H^{-0.2075}\end{array}$ \\
\hline Aggidis et al. [12] & $C=18552 \cdot P^{0.56} \cdot H^{-0.36}$ \\
\hline
\end{tabular}

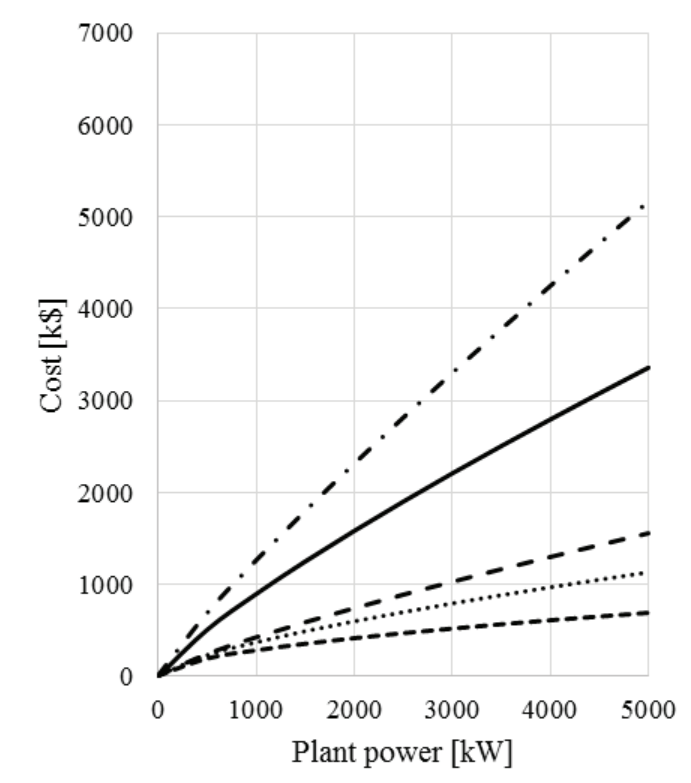

$$
\begin{aligned}
& \text {....... Gordon and Penman } \\
& \text { - Gulliver and Dotan } \\
& \ldots \text { - Singal and Saini } \\
& \text { - - Kaldellis }
\end{aligned}
$$

Fig. 1. Cost functions with respect to plant power for net heads equal to 5 (A), 25 (B) and 100 [m] (C). 
Fig. 1 clearly shows that results obtained with various formulas can differ greatly. Particularly formula by Kaldellis stands out - for each value of net head, it estimates cost of electro-mechanical equipment much higher than other formulas. Only for small head value, formula by Gulliver and Dotan gives similar results. Besides, formula by Gullliver and Dotan also stands out from the others, giving higher estimates than three

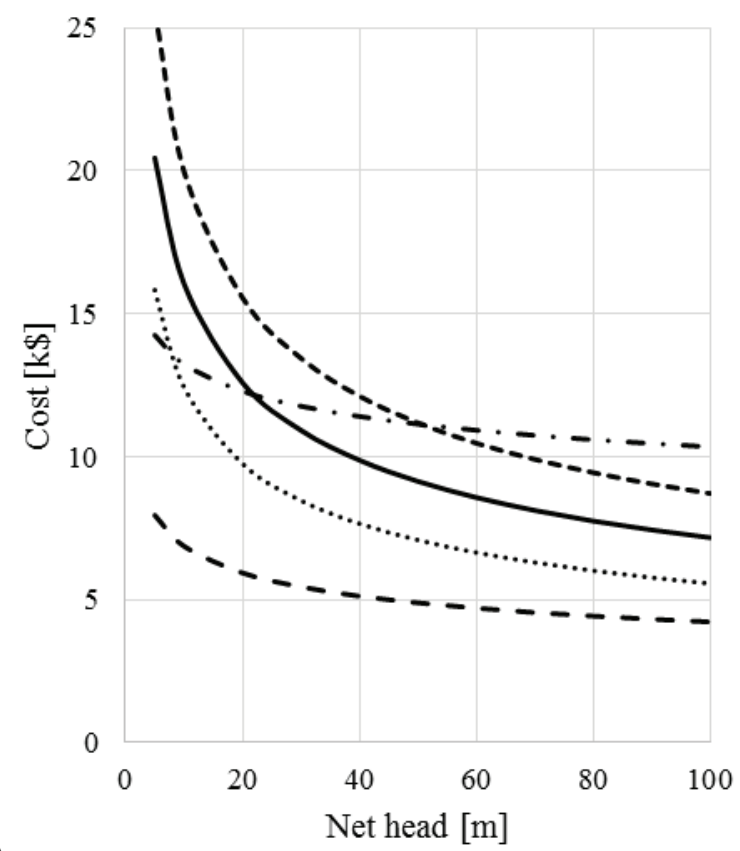

A

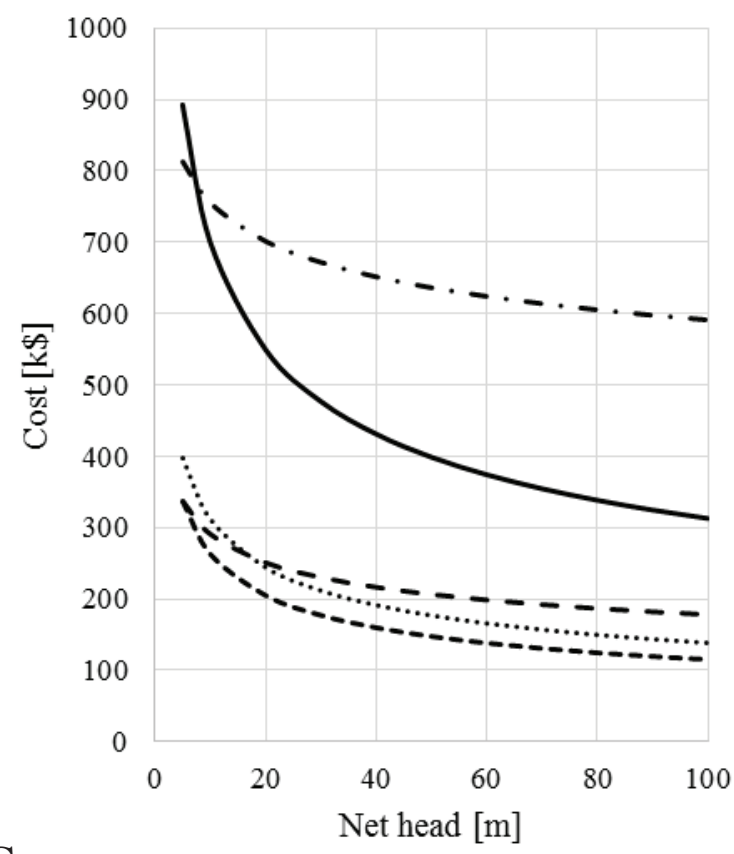

C remaining formulas also for higher net head values - not as high as Kaldellis' but still significantly higher. Formulas by Singal and Saini, Gordon and Penman, as well as Aggidis et al., gives results much closer to each other, but still considerably different. It should be noted that the most similar results were obtained using the formulas derived in 1979 and 2008, and that the formula by Aggidis et al. always gives the smallest estimates.

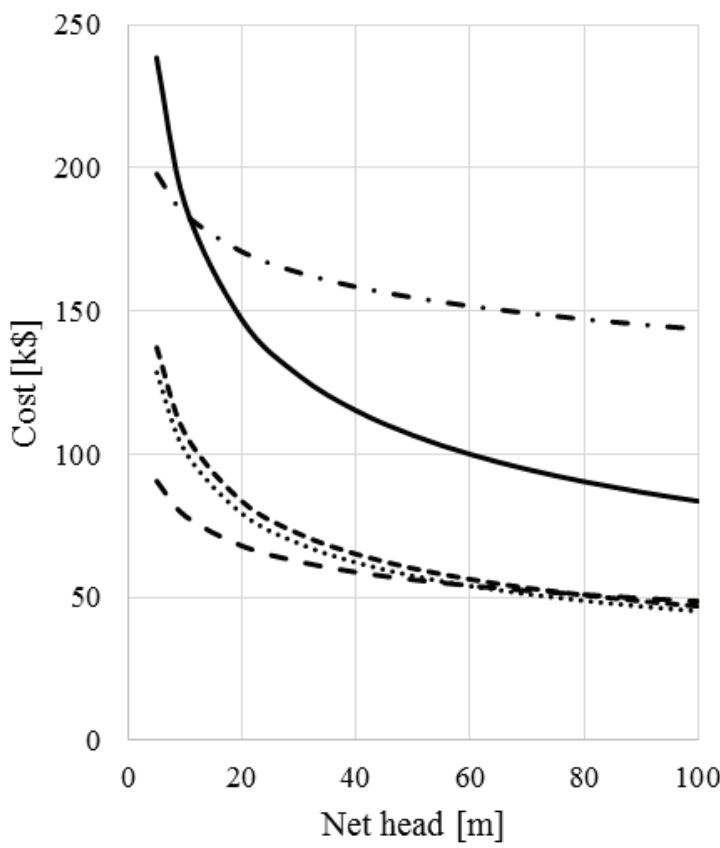

B

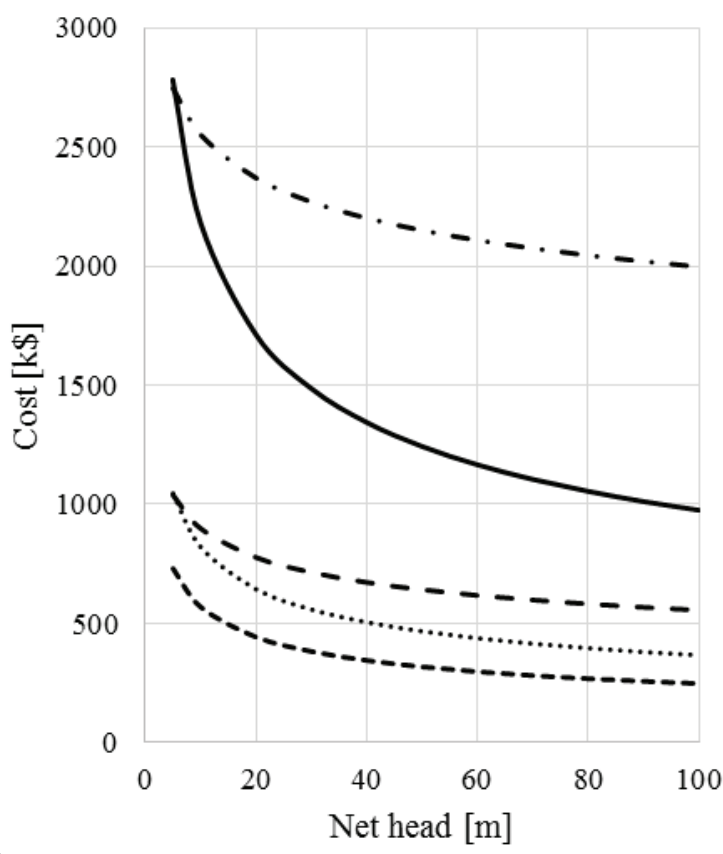

D

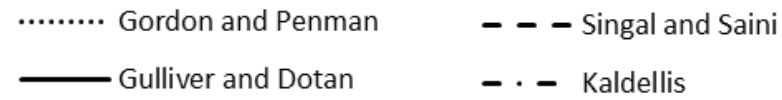

--- Aggidis et al.

Fig. 2. Cost functions with respect to net head for plant powers equal to 5 (A), 100 (B) and 500 [kW] (C), and 2 [MW] (D). 
Fig. 2 confirms conclusions that were drawn based on Fig. 1, i.e. estimates obtained with the use of various formulas differ significantly. Kaldellis' formula still gives highest estimates, except for cases of plants with small power and net heads. Intuitively expected cost reduction resulting from increase of net head has varying dynamics, depending on the approach. For example, for the same power $(500[\mathrm{~kW}])$, increase of net head from 5 to $100[\mathrm{~m}]$ can theoretically give approx. $65 \%$ decrease in cost (Gulliver and Dotan, Gordon and Penman, and Aggidis et al. formulas) as well as approx. 50\% (Singal and Saini formula) or $27 \%$ decrease (Kaldellis formula), with a very different starting cost.

The same conclusion concerning dynamics of cost volatility results from the analysis of Fig. 1 - increase of cost being consequence of increase in plant power can have very different growth dynamics, depending on the used formula.

It is worth mentioning that the literature study shows that theoretical values obtained with the use of different methods for the actual small hydropower plants are also significantly different $[12,13]$. Comparison with reals cost shows great underestimations or overestimations of the cost $[12,13]$. Such observation leads to the conclusion that formulas allowing to estimate the cost of investment in electro-mechanical equipment for small hydropower plants should be used very carefully, i.e. with particular regard to the considered project.

It is particularly worth to look up for the literature case studies in the context of finding an existing power plant(s) with characteristics similar to the designed one. Special attention should be payed to the formulas considering turbine type [12-14], but in our opinion, more research on that subject, considering more case studies in various geographical locations, should be performed.

The above remark applies not only to planning investments in small hydropower plants, but also to research work. The simple use of chosen formula [16, 17] raises the question of the accuracy of the obtained results and reliability of the economic analysis, which can be extremely important if the decision on the real investment is to be made.

\section{Conclusions}

The following conclusions can be drawn based on the performed study:

1. Significant differences in results obtained by using different formulas allowing estimation of the cost of investment in electro-mechanical equipment for small hydropower plants were observed.

2. Careful use of the analysed formulas is recommended.

3. In case of planning the investment in small hydropower plant, it is always advisable to refer to the proper case study - as similar to the one being designed as it is possible.

4. There is a need for wide studies based on national investments in small hydropower plants that would allow to develop equations based on local data and to supplement the case studies database.

5. The obtained formulas would let to determinate the costs of modernization or a new construction of small hydropower plant more precisely.

6. Special attention should be payed to formulas considering turbine type, as it can be the key to the more precise estimates of the cost of investment in electro-mechanical equipment for small hydropower plants.

7. Simulation of the cost of electro-mechanical equipment for small hydropower plants based on unification of the formulas found in literature allows deeper discussion of the problem, as well as drawing broader conclusions.

8. Such approach is novel in the context of investment in small hydropower plants and, in our opinion, it should be used more frequently, as it allows obtaining and then analysing families of curves, instead of referring only to specific cases.

\section{References}

1. L.J. Bracken, H.A. Bulkeley, C.M. Maynard, Energ. Pol. 68(C), 92 (2014)

2. S. Mishra, S.K. Singal, D.K. Khatod, Ren. Sust Energ. Rev 15(8), 3862 (2011)

3. J.L. Gordon, A.C. Penman, J. Water Power Dam. Constr. 31(9), 46 (1979)

4. J.S. Gulliver, A. Dotan, J. Energ. Eng. 110(3), 204 (1984)

5. H.M. Whittington, A.R. Wallace, D.S. Henderson, Proc. Third Int. Conf. Small Hydro, Int. Water Power \& Dam. Constr., 182 (1988)

6. N.G. Voros, C.T. Kiranoudis, Z.B. Maroulis, Ren. Energ. 19(4), 545 (2000)

7. D. Papantonis, Small hydro power stations (Simeon, Athens, 2001)

8. J.L. Gordon, Hydro Rev. Wordw. 11(1), 37 (2003)

9. J.K. Kaldellis, Energ. Pol. 35(4), 2187 (2007)

10. S.K. Singal, R.P. Saini, Ren. Energ. 33(12), 2549 (2008)

11. G.A. Aggidis, E. Luchinskaya, R. Rothschild, D.C. Howard, Ren. Energ. 35(12), 2632 (2010)

12. B. Ogayar, P.G. Vidal, Ren. Energ. 34(11), 2501 (2009)

13. G. Cavazzini, A. Santolin, G. Pavesi, G. Ardizzon, Energy 103, 746 (2016)

14. A. Santolin, G. Cavazzini, G. Pavesi, G. Ardizzon, A. Rossetti, Energ. Convers. Manage. 52(7), 2533 (2011)

15. Guide on How to develop a small hydropower plant (ESHA, 2004)

16. D.A. Zema, A. Nicotra, V. Tamburino, S.M. Zimbone, Ren. Energ. 85, 498 (2016)

17. D.K. Okot, Ren. Sust Energ. Rev 26, 515 (2013) 